Atmos. Chem. Phys., 10, 769-775, 2010

www.atmos-chem-phys.net/10/769/2010/

(C) Author(s) 2010. This work is distributed under

the Creative Commons Attribution 3.0 License.

\title{
Weather response to a large wind turbine array
}

\author{
D. B. Barrie and D. B. Kirk-Davidoff \\ University of Maryland Department of Atmospheric and Oceanic Science, College Park, MD, USA
}

Received: 8 December 2008 - Published in Atmos. Chem. Phys. Discuss.: 29 January 2009

Revised: 8 January 2010 - Accepted: 15 January 2010 - Published: 26 January 2010

\begin{abstract}
Electrical generation by wind turbines is increasing rapidly, and has been projected to satisfy $15 \%$ of world electric demand by 2030. The extensive installation of wind farms would alter surface roughness and significantly impact the atmospheric circulation due to the additional surface roughness forcing. This forcing could be changed deliberately by adjusting the attitude of the turbine blades with respect to the wind, which would enable the "management" of a large array of wind turbines. Using a General Circulation Model (GCM), we represent a continent-scale wind farm as a distributed array of surface roughness elements. Here we show that initial disturbances caused by a step change in roughness grow within four and a half days such that the flow is altered at synoptic scales. The growth rate of the induced perturbations is largest in regions of high atmospheric instability. For a roughness change imposed over North America, the induced perturbations involve substantial changes in the track and development of cyclones over the North Atlantic, and the magnitude of the perturbations rises above the level of forecast uncertainty.
\end{abstract}

\section{Introduction}

The development of numerical weather prediction (NWP) by John von Neumann and Jule Charney was motivated in part by a desire to influence weather at a distance (Kwa, 2002). However, von Neumann recognized that the practical means to exert control on large-scale weather did not yet exist (Kwa, 2002). While NWP was being developed, Irving Langmuir and Vincent Schaefer's work on cloud seeding provided an early method for manipulating precipitating systems (Langmuir, 1950; Schaefer, 1946). Langmuir (1950) suggested

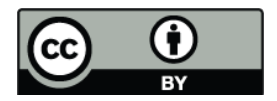

Correspondence to: D. B. Barrie (dbarrie@atmos.umd.edu) that cloud seeding could be used to suppress hurricanes by altering early convective growth in tropical disturbances. However, in subsequent attempts at cyclonic-scale modification, such as Project Stormfury, investigators did not have the ability to introduce perturbations in the circulation larger than the observational uncertainty, or knowledge of the error growth mode structure sufficient to match the perturbations to the growing modes (Willoughby et al., 1985).

The chaotic growth of small initial perturbations in the atmosphere (Lorenz, 1963) has both positive and negative implications for weather modification strategies. A small perturbation in the atmosphere may eventually become large enough to have detectable consequences for weather. However, chaos limits weather predictability to a few weeks, since the various atmospheric states consistent with observational uncertainty diverge completely from one another over that time (Lorenz, 1969). Thus, deliberate synoptic-scale weather modification requires the ability to introduce perturbations that are larger than observational uncertainty. These perturbations must also project onto atmospheric modes with the potential to grow in a desired direction. Hoffman (2002) proposed a program of global weather modification in which weather would be optimized by systematically adjusting all human controlled phenomena that could influence the atmosphere's flow. Hoffman et al. (2006) demonstrated in a model that hurricanes could be steered by creating an ideal initial perturbation in the temperature field. However, the introduction of that perturbation required impractically large energy inputs.

Previous modeling studies have shown that significant mean changes in climate patterns result from the introduction of large-scale wind farms (Keith et al., 2004; Kirk-Davidoff and Keith, 2008). Effects on meteorology have also been demonstrated for wind farms of a smaller size in a regional model (Baidya Roy et al., 2004). Baidya Roy performed a modeling study of a wind farm containing 10000 turbines, positioned in Oklahoma. In this study, the wind farm was

Published by Copernicus Publications on behalf of the European Geosciences Union. 
modeled as an elevated momentum sink. The wind farm slowed hub-height wind speeds substantially, and also modified surface fluxes by a considerable amount. These findings suggest that a step change in the effective roughness of a large-scale wind farm might introduce a perturbation in the atmospheric flow larger than the observational uncertainty. In this study, we examine the evolution of perturbations caused by such step changes in a fixed array of wind turbines within a synoptic forecast period. The continental scale of this wind farm is consonant with that of growing synopticscale modes, and the amplitude of the roughness forcing is large when compared with the typical background observational uncertainty of the mean wind in model initializations at the National Center for Environmental Prediction. Although synoptic-scale perturbations grow slowly relative to convective-scale perturbations (Schubert and Suarez, 1989), they saturate at higher amplitudes than convective modes (Toth and Kalnay, 1993), suggesting that weather modification may be possible by taking advantage of the short-term predictability of mid-latitude instabilities. While large-scale wind turbine installations like those discussed in this paper do not yet exist, no known resource limitations would prevent their construction in the near future.

\section{The potential for large-scale wind farms}

The worldwide wind energy potential has been assessed at 72 Terawatts (TW) (Archer and Jacobson, 2005). Total worldwide electric power consumption is projected nearly to double from 1.9 to 3.5 TW between 2004 and 2030 (Dorman et al., 2007). A large contribution from wind energy is typically proposed when modeling the power supply system under carbon constraints (e.g. Aubrey et al., 2006; Department of Energy, 2008; Pacala and Socolow, 2004). Continued rapid growth of the United States wind industry will result in substantial development of its wind resource. The central United States will be a focal point of this development because it hosts the largest contiguous wind resource of any on-shore region in the United States (Elliott et al., 1986). Turbine installation costs are lower there than in any other region of the United States (Wiser and Bolinger, 2004). In addition, wind farm developers are willing to pay leasing fees to farmers for the use of their land to build wind farms, resulting in a substantial source of supplemental income for farmers in the region (Department of Energy, 2004).

\section{Model description}

Individual wind turbines affect local momentum transports through the creation of a cross-blade pressure gradient and turbulent wakes (Medici, 2004). The aggregate impact of an array of wind turbines can be parameterized by a single roughness length (Vermeer et al., 2003). This is the approach we have taken using the National Center for Atmospheric
Research Community Atmosphere Model 3.0 (CAM 3.0) (Collins et al., 2006).

\subsection{Wind farms as a surface roughness length}

The wind farm in this study was represented as an increase in surface roughness instead of as an elevated momentum sink. The second layer midpoint in CAM is located at $970 \mathrm{hPa}$, which is equivalent to approximately $250 \mathrm{~m}$ in elevation. This is a substantially higher elevation than the typical height of a turbine hub, which is around $100 \mathrm{~m}$. Thus, the turbines could not be realistically represented as elevated momentum sinks and turbulent kinetic energy sources. The wind farm parameterizations in Keith et al. (2004) were similarly limited by coarse vertical resolution. If models with higher vertical resolution were used in our future work, we would adopt the momentum sink approach.

CAM 3.0 describes land surface characteristics using the spatial and temporal distribution of 16 Plant Functional Types (PFTs) across the land surface. Each land grid point can support four unique PFTs, with coverage adding up to $100 \%$ over each grid point (Barlage and Zeng, 2004). We have converted an unused PFT into a wind farm subtype, with a "canopy" height of $156 \mathrm{~m}$, a ratio of roughness length to canopy height of 0.022 , and a displacement height of zero meters.

Wind turbine roughness length was calculated using the Lettau method (Lettau, 1969):

$z_{o}=0.5 h^{*} \frac{s}{S}$

where $z_{o}$ is the roughness length in meters, $h^{*}$ is the average height of one roughness element (the diameter of the turbine rotor face), $s$ is the frontal area (the area swept by the blades), and $S$ is a measure of the density of roughness elements (the amount of horizontal area occupied by one turbine). Using values of $112 \mathrm{~m}$ for $h^{*}, 9852 \mathrm{~m}^{2}$ for $s$ (assuming a $56 \mathrm{~m}$ long blade), and $0.16 \mathrm{~km}^{2}$ for $S$, the resulting value of $z_{o}$ was $3.45 \mathrm{~m}$. This was the value inserted in the model's vegetation parameter tables. However, the wind farm PFT was set to occupy only $25 \%$ of the surface area within the wind farm region so that other forms of vegetation were represented within the wind farm to provide realistic moisture fluxes. Thus, each turbine effectively occupied approximately $0.64 \mathrm{~km}^{2}$, for which the Lettau method would yield a $z_{o}$ of $0.86 \mathrm{~m}$. To derive a value for the area occupied by one turbine, turbine spacing was assumed to be $800 \mathrm{~m}$. This estimate is consistent with observed values and typical assumptions in the wind energy literature (Elliott et al., 1991; $\mathrm{Lu}$ et al., 2009). By using a surface roughness length to represent the wind farm, we are treating it in a similar manner as other surface obstacles such as vegetation or urban areas.

As a means of estimating surface roughness for an array of objects, the Lettau method is elegant in its simplicity, and has held up well under scrutiny. Wieringa (1993) indicated 
that the Lettau method was accurate for object arrays with arrangements ranging from purely homogeneous to moderately heterogeneous. The Lettau method has been shown to be accurate for object arrays even more complex than the ones studied by Wieringa (Petersen, 1997). The Lettau method is limited to sparsely packed object arrays, or situations where the objects have minimal aerodynamic impacts on each other. When object frontal area divided by object density exceeds 0.2 to 0.3 , the formula fails (MacDonald et al., 1998).

Wind turbines arranged in a wind farm present an optimal case for estimation of surface roughness by the Lettau method. In our study, wind turbine rotor area was $9852 \mathrm{~m}^{2}$. Each turbine occupied approximately $0.64 \mathrm{~km}^{2}$. Dividing the frontal area by the area occupied by each turbine yields a value of 0.015 , which is an order of magnitude less than the limit on the Lettau method proposed by MacDonald et al. (1998). This indicates that the Lettau method is acceptable for estimating wind farm surface roughness, at least until detailed field or laboratory studies are carried out. Frandsen (2007) confirms this finding. The estimate of surface roughness derived from the Lettau method is true for an array of static objects. The contribution of the moving turbine parts to the actual value of surface roughness is unknown.

\subsection{Size of the wind farm}

The wind farm simulated in this study occupies $23 \%$ of the North American land area and is positioned in the central United States and south central Canada. Figure 1 shows the extent of the wind farm, as indicated by the rectangular box.

Kirk-Davidoff and Keith (2008) simulated the effect of an area of increased surface drag on the flow in a shallow water model. In one experiment, as the area of the region of increased drag was enlarged, the downstream impact was noted to increase approximately linearly in response. The magnitude of the downstream impact reached a maximum when the size of the drag region equaled approximately one third of the wavelength of the stationary Rossby wave solution for the shallow water model's basic state. This finding suggests there is an optimal size scale at which a surface drag feature such as a wind farm will maximally project onto the modes of instability of the atmosphere.

In early tests of the modeling studies described in this paper, it was found that a substantially smaller wind farm, with an area one quarter the size of the wind farm described in this paper, did not cause a large downstream impact. The perturbation induced by the smaller wind farm's drag had a much weaker impact on upper level winds, leading to a lack of noticeable downstream effects. On the other hand, the scale of the wind farm described throughout this paper is larger than the area of surface damping that elicited a maximum downstream response in the shallow water model used by KirkDavidoff and Keith (2008). We expect that a modest change in the size of the wind farm studied here would have little ef-

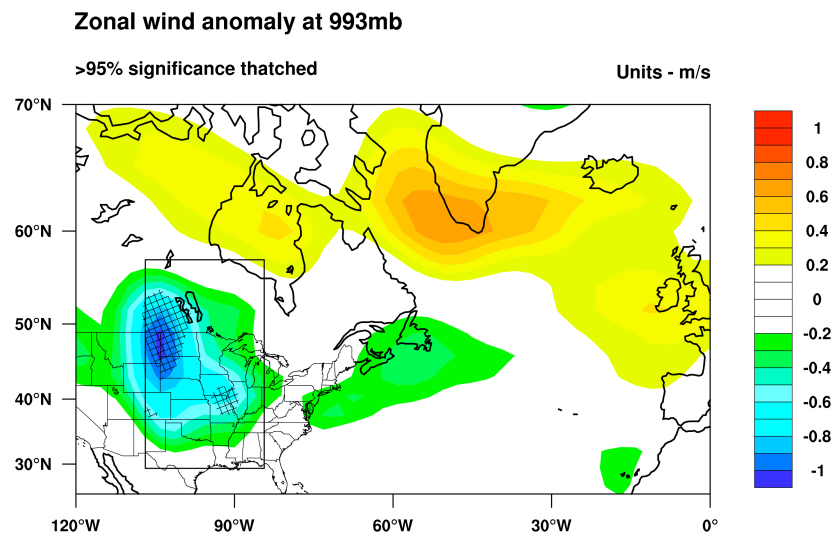

Fig. 1. $993 \mathrm{hPa}$ zonal wind anomaly. The mean difference in the eastward wind in the lowest model level between the control and perturbed model runs highlights regions of atmospheric modification. Regions where significance exceeds $95 \%$, as determined by a Student's t-test, are thatched. The wind farm is located within the rectangular box over the central United States and central Canada. Areas of the wind farm located over water are masked out during the model runs.

fect on the magnitude of the downstream response. Ongoing work will characterize scale dependence in more detail.

\subsection{Model runs}

The model was run with fixed sea surface temperatures at T42 resolution for six years with the wind farm present. Seventy-two case studies were created by running the model in branch mode using the monthly restart files created during the six years of the control run. Each of the branch runs lasted for one month. For these case studies, the wind farm PFT roughness was reduced by $83 \%$ to simulate the minimal drag of a turbine profile, where the face of the turbine is turned so that it is orthogonal to the wind direction. The branch runs simulate the effect of a sudden, large reduction in surface roughness on the atmosphere.

One case study was examined in detail to determine the extent to which the observed atmospheric perturbations are sensitive to initial conditions. Five sets of initial conditions were created by adding to the temperature field a normally distributed random perturbation with a standard deviation equal to $1 \%$ of the standard deviation of the temperature field, to represent observational uncertainty in the initial conditions for the forecast.

\subsection{Dissipation due to surface roughness}

We derived a total maximum energy output for our hypothetical wind farm of $2.48 \mathrm{TW}$ using 12-hourly lowest model level winds (corresponding to an altitude of approximately $80 \mathrm{~m}$ ), blade lengths of $56 \mathrm{~m}$, typical turbine spacing $\left(.59 \mathrm{~km}^{2}\right.$ per turbine), and the Betz limit (59.3\%). The Betz limit describes 
Zonal wind vs. stress for wind farm on and off cases

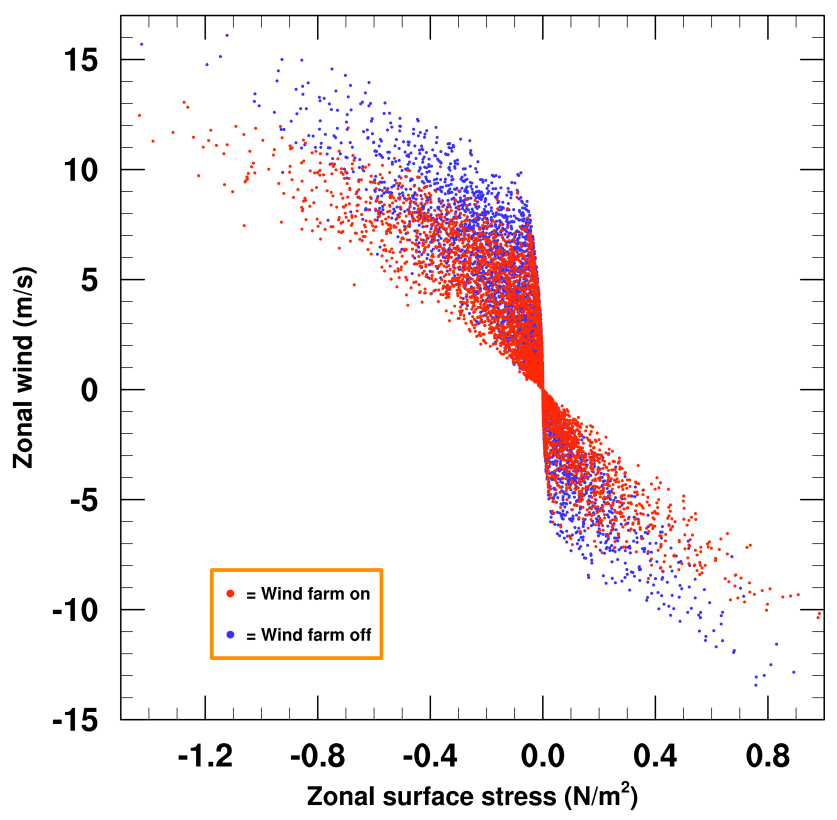

Fig. 2. The relationship between zonal wind speed and surface stress. When the wind farm is present, the surface stress is larger for a given wind speed than when the wind farm is absent.

the maximum amount of incoming kinetic energy a wind turbine can convert to mechanical energy. This is the power that would be produced if perfectly efficient turbines of unlimited nameplate capacity were installed over the entire region.

Power dissipation in the wind farm region was calculated to be, on average, 9.66 TW. This calculation used wind and surface stress data. Each grid square is only partially covered by wind turbines, so some of this dissipation is due to the other types of surface cover. Because of this, it is difficult to separate the dissipation due to the wind farm from the dissipation due to natural vegetation. One way to estimate the added dissipation of the wind farm is to look at the model time step $12 \mathrm{~h}$ after the step change in surface roughness across all of the case studies. At this time step, differences between the case and control results are due mostly to the impact of the wind farm instead of error growth due to atmospheric chaos. The difference in dissipation is $0.41 \mathrm{TW}$, which indicates a small addition to the usual dissipation over the wind farm area because of the turbines. This indicates that the energy normally dissipated by crops, trees, and other natural land cover types is instead dissipated by the turbines, with a small additional dissipation due to the high roughness value of the turbines. We interpret this finding as being indicative of a shift from conversion of kinetic energy to heat via the motion of vegetation, to conversion of kinetic energy to electrical power in the wind turbine generators. At the sub-grid level of the land surface parameterization, wind stress increases despite the lower mean wind over the frac- tional grid squares where the wind turbines are located, as can be seen in Fig. 2. This occurs because the ratio of the wind stress to the wind speed increases with the increase in roughness length (see "Eq. (4.434)" in Collins et al., 2004). At the same time, wind stress over the fractional grid squares with vegetation coverage decreases due to the reduced wind speed.

\section{Results}

Figure 1 shows the mean difference between the case and control runs in the eastward wind field at the lowest model level. The impacts are, on average, focused within the wind farm, where there is a slowing of the wind. There is also a region of zonal acceleration extending from Northern Canada to Western Europe. The structure of the anomaly is similar to that found in a previous 20 year model run with and without wind farm forcing, and it arises from the dynamical adjustment of the atmosphere to the surface roughness anomaly (Kirk-Davidoff and Keith, 2008).

During the first few days following the decrease in magnitude of the surface roughness perturbation in each case, we observe highly localized wind and temperature anomalies that are contained primarily within the wind farm and depend strongly on the overlying meteorological conditions. Over the following days, the impacts move downstream and eventually reach the North Atlantic. There the anomalies grow, and their magnitudes exceed the magnitude of the response at the wind farm. This is shown in Fig. 3a, a Hovmoller plot of the standard deviation over the 72 case studies. The zonal wind anomaly in the lowest model layer is depicted in the plot and was averaged over 29 to $57^{\circ} \mathrm{N}$ to capture the effects in the latitude band downstream of the wind farm. The horizontal axis is longitude and the vertical axis is time. Figures $3 \mathrm{~b}$ and $\mathrm{c}$ show time slices of the Hovmoller plot, illustrating the downstream development of the anomaly patterns. When the wind farm is first turned off, the largest anomalies are located at the wind farm site. After four days have passed, the effect of the wind farm is most prominent in the North Atlantic, and reaches the North Pacific after one week. The anomalies grow faster within the Atlantic and Pacific storm tracks than over land. After two weeks have elapsed, the perturbed run has largely diverged from the original run, obscuring the structure of the wind farm effects, although the largest anomalies are still found over the northern ocean basins.

Empirical orthogonal function (EOF) analysis was performed on each day post-disturbance, with case number as the primary dimension. The domain of the analysis focused on the region downstream of the wind farm. Four and a half days after the surface roughness change, the dominant EOF components display a wave-like structure located downstream of the wind farm, and extending into the North Atlantic (Fig. 4). The first two EOF components, which 
EOF of day 4 geopotential height at $697 \mathrm{mb}$
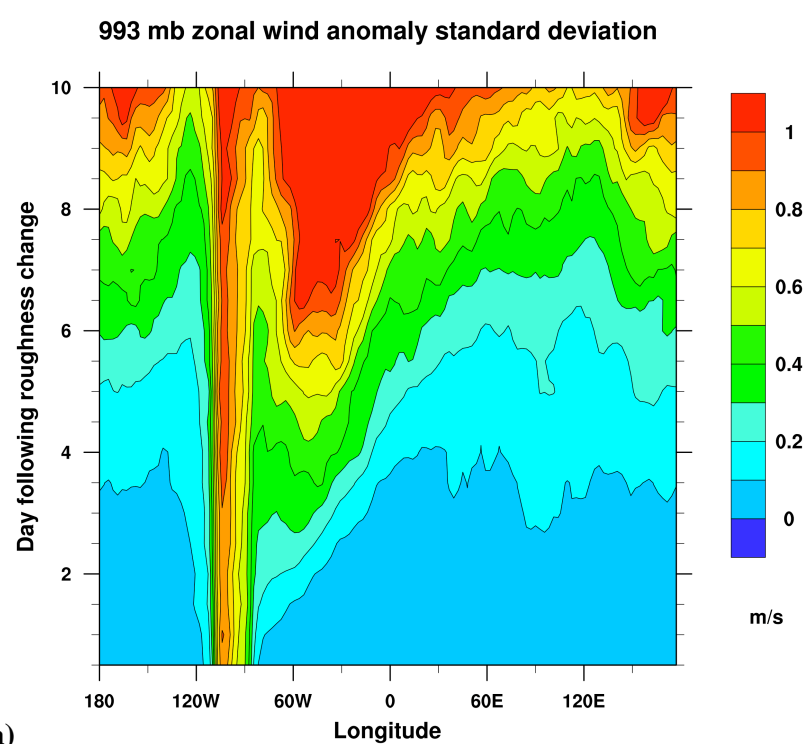

(a)

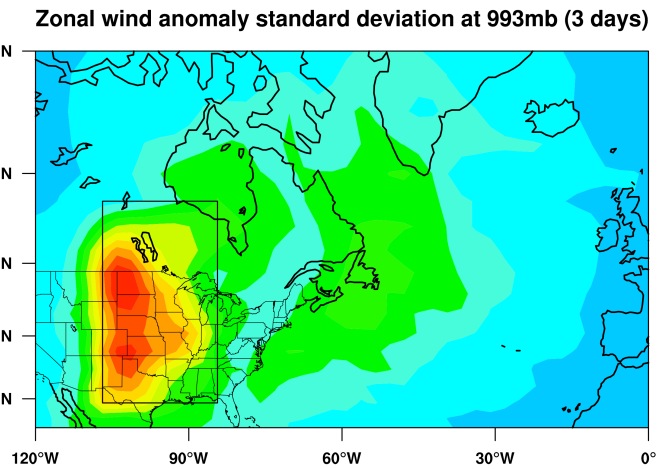

(b)

Zonal wind anomaly standard deviation at $993 \mathrm{mb}$ (5.5 days)
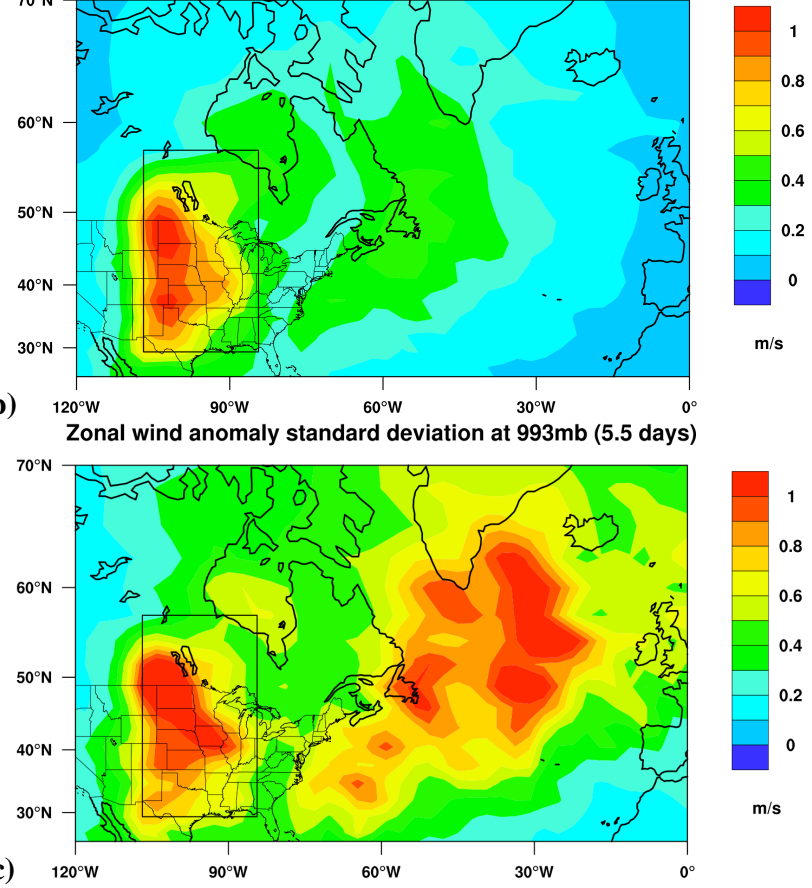

$\mathrm{m} / \mathrm{s}$

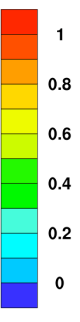

$\mathrm{m} / \mathrm{s}$

Fig. 3. Growth and propagation of anomalies. (a) A Hovmoller plot shows the standard deviation of anomalies versus forecast lead time and longitude, highlighting the growth rate and group velocity of perturbations. (b) The standard deviation over all cases of the anomalous lower tropospheric zonal wind field one half day after the roughness change is depicted. This plot is equivalent to a time slice of panel (a) at time day $=3$. The largest effects are confined to the wind farm. (c) Same as panel (b) except at time day=5.5. The largest effects are now located over the North Atlantic.

\section{EOF 1}
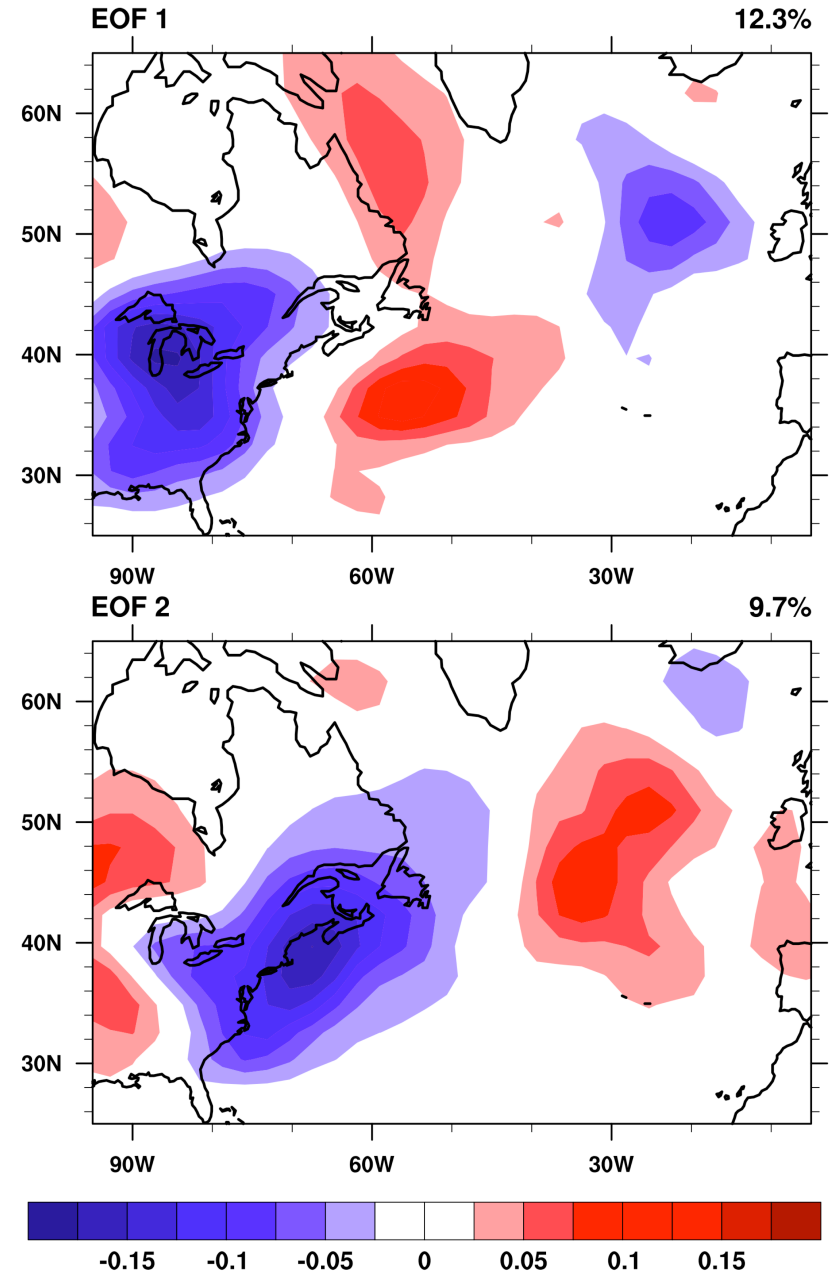

Fig. 4. EOF analysis of the day four $697 \mathrm{hPa}$ zonal wind. The first two components of an EOF analysis are displayed. They depict the two largest modes of variability associated with the surface roughness perturbation.

explain $22 \%$ of the total variability, are approximately in quadrature and depict a growing baroclinic mode. Although the magnitude of the first EOF component is small, the pattern is striking. Of the first ten EOF components, nine show varying downstream wave patterns. Cumulatively, these nine components account for $52 \%$ of the total variability, which indicates that the wind farm induces large instabilities in the downstream flow after a few days have elapsed from the roughness perturbation. A visual inspection of the zonal wind anomalies at $697 \mathrm{hPa}$ over all of the case studies reveals a number of instances where a wave train occurs. Wave amplitude, wavelength, and channel width vary greatly across all of the cases, but each is confined to the central North Atlantic.

The case studies were also examined to find particularly large impacts on individual weather systems. In one case, 
Geopotential height anomaly at $510 \mathrm{mb}$ ( 4.5 days)

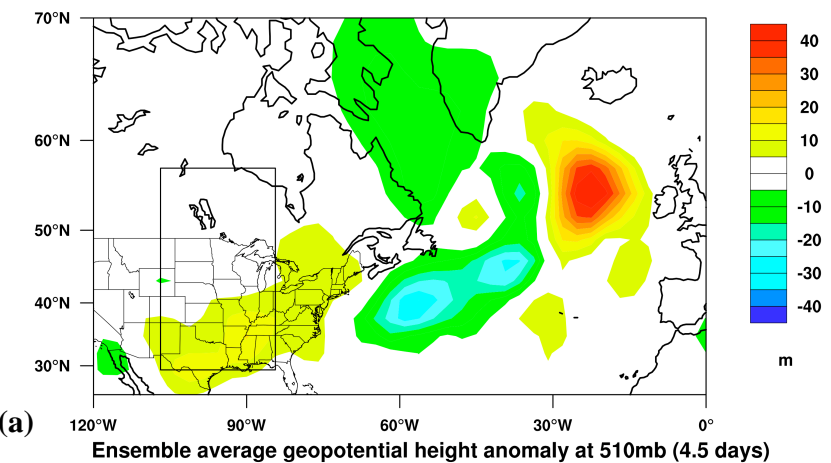

Standard deviation across ensemble members is contoured

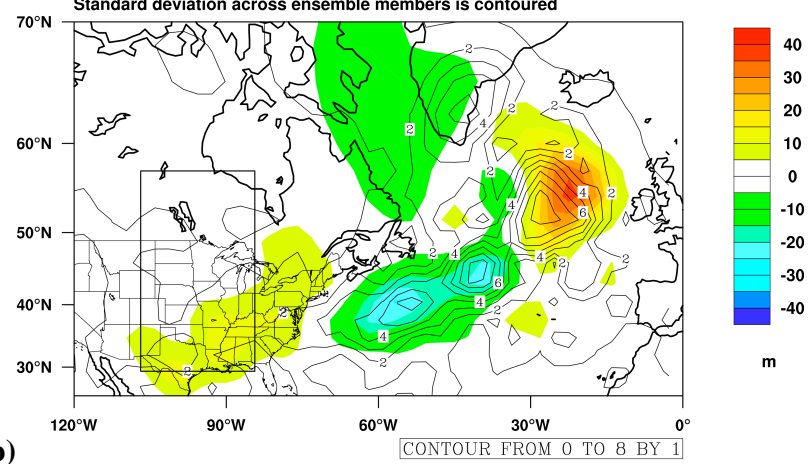

(b)

Fig. 5. $510 \mathrm{hPa}$ geopotential height. These plots of geopotential height depict a particular case where a large modification of weather occurred four and a half days after the surface roughness modification. (a) The anomaly field (calculated as the difference between the case with the wind farm on, and the case with it off) shows changes in geopotential height of approximately $40 \mathrm{~m}$. (b) The results of an ensemble study of the case depicted in panel (a) is shown. The average anomalies are shaded, and the standard deviation across the ensemble components is shown in contours.

a $40 \mathrm{~m}$ anomaly was observed in the $510 \mathrm{hPa}$ geopotential height field four and a half days after the surface roughness change was triggered in the model. This is shown in Fig. 5a. The anomaly observed in this case exceeds the average error in a 5-day forecast of $500 \mathrm{hPa}$ geopotential height over the North Atlantic, which is rarely larger than $20 \mathrm{~m}$. We tested this result by restarting the case using five different sets of randomly perturbed initial conditions. The ensemble average and standard deviation is presented in Fig. 5b. The structure and magnitude of the average anomaly is similar to the result shown in Fig. 5a. The standard deviation across the five ensemble members indicates that the ensemble error is small. The results of the ensemble imply that the induced perturbation persists through five different, randomly perturbed tests.

\section{Conclusions}

Wind farms as large as those studied in the paper do not yet exist, and as such, we view this work as a theoretical problem with the potential for real world applications in the coming decades. The study presented here depicts a strong downstream impact caused by a large surface roughness perturbation in a GCM. We have assumed that the active control of turbine orientation could produce a time-dependent change in surface roughness. Atmospheric anomalies initially develop at the wind farm site due to a slowing of the obstructed wind. The anomalies propagate downstream as a variety of baroclinic and barotropic modes, and grow quickly when they reach the North Atlantic. These responses occur within a short forecast timeframe, which suggests that predictable influences on weather may be possible. This study utilized an array of highly variable initial conditions to initialize the model. Ongoing work will catalog the initial meteorological conditions necessary to generate predictable and controlled downstream effects caused by wind farms. We performed an ensemble study of one particular case with randomized initial conditions chosen for both the wind farm and the wind farm absent cases that showed that the atmospheric perturbation persists across the ensemble members. We will continue to study the wind farm effects in an ensemble context to determine the conditions necessary for induced perturbations to project strongly onto the fastest modes of error growth. This will illustrate the statistical significance and regularity of downstream changes in the atmosphere. There are open questions regarding the importance of the size of the wind farm, the sensitivity of the impacts to the value of surface roughness, the amount of time that the wind farm would have to be turned off, and the location of the wind farm with respect to overlying atmospheric structures such as the jet stream. We are continuing this work by studying these issues in greater detail.

Acknowledgements. We thank Eugenia Kalnay for her comments and suggestions. We acknowledge Juliana Rew and Samuel Levis, at the National Center for Atmospheric Research (NCAR), for their assistance. This work was made possible by NSF grant ATM-0457515, and a donation of modeling time by NCAR.

Edited by: W. E. Asher

\section{References}

Archer, C. L. and Jacobson, M. Z.: Evaluation of global wind power, J. Geophys. Res., 110, D12110, doi:10.1029/2004JD005462. 2005.

Aubrey, C., Pullen, A., Zervos, A., and Teske, S.: Global wind energy outlook 2006, Global Wind Energy Council (GWEC), Brussels, 2006.

Baidya Roy, S., Pacala, S. W., and Walko, R. L.: Can wind farms affect local meteorology?, J. Geophys. Res., 109, D19101, doi:10.1029/2004JD004763, 2004. 
Barlage, M. and Zeng, X.: The effects of observed fractional vegetation cover on the land surface climatology of the community land model, J. Hydrometeorol., 5, 823-830, 2004.

Collins, W. D., Rasch, P. J., Boville, B. A., et al.: Description of the NCAR Community Atmosphere Model (CAM 3.0), NCAR technical note, NCAR/TN-464+STR, 2004.

Collins, W. D., Bitz, C. M., Blackmon, M. L., et al.: The community climate system model version 3 (CCSM3), J. Climate, 19, 21222143, 2006.

Department of Energy: Wind Energy for Rural Economic Development, United States Department of Energy, Office of Energy Efficiency and Renewable Energy, Washington, DOE/GO-1020041826, 2004.

Department of Energy: 20\% wind energy by 2030 increasing wind energy's contribution to the U.S. electricity supply, United States Department of Energy, Office of Energy Efficiency and Renewable Energy, Washington, DOE/GO-102008-2567, 2008.

Dorman, L. E., Khilji, N., Sastri, B., et al.: International Energy Outlook 2007, United States Department of Energy, Office of Integrated Analysis and Forecasting, Washington, DOE/EIA0484(2007), 2007.

Elliott, D., Holladay, C. G., Barchet, W. R., Foote, H. P., and Sandusky, W. F.: Wind energy resource atlas of the United States, Department of Energy, DOE/CH 10093-4, 1986.

Elliott, D. L., Wendell, L. L., and Gower, G. L.: An Assessment of the Available Windy Land Area and Wind Energy Potential in the Contiguous United States, Pacific Northwest Laboratory, PNL-7789, 1991.

Frandsen, S.: Turbulence and turbulence-generated structural loading in wind turbin clusters, Riso National Laboratory, Riso-R1188(EN), 2007.

Hoffman, R. N.: Controlling the global weather, B. Am. Meteorol. Soc., 83, 241-248, 2002.

Hoffman, R. N., Henderson, J. M., Leidner, S. M., Grassotti, C., and Nehrkorn, T.: The response of damaging winds of a simulated tropical cyclone to finite-amplitude perturbations of different variables, J. Atmos. Sci., 63, 1924-1937, 2006.

Keith, D., DeCarolis, J. F., Denkenberger, D. C., et al.: The influence of large-scale wind power on global climate, P. Natl. Acad. Sci. USA, 101, 16115-16120, 2004.

Kirk-Davidoff, D. B. and Keith, D.: On the climate impact of surface roughness anomalies, J. Atmos. Sci., 85, 2215-2234, 2008.

Kwa, C.: The rise and fall of weather modification: changes in American attitudes towards technology, nature, and society, Changing the Atmosphere: Expert Knowledge and Environmental Governance, 1st ed., edited by: Miller, C., pp. 135-165, The MIT Press, Cambridge, 2001.
Langmuir, I.: Control of precipitation from cumulus clouds by various seeding techniques, Science, 112, 35-41, 1950.

Lettau, H.: Note on aerodynamic roughness-parameter estimation on the basis of roughness-element description, J. Appl. Meteorol., 8, 828-832, 1969.

Lorenz, E. N.: Deterministic nonperiodic flow, J. Atmos. Sci., 20, 130-141, 1963.

Lorenz, E. N.: Atmospheric predictability as revealed by naturally occurring analogues, J. Atmos. Sci., 26, 636-646, 1969.

Lu, X., McElroy, M., and Kiviluoma, J.: Global potential for wind-generated electricity, P. Natl. Acad. Sci. USA, 106, 10933 10938, 2009.

Macdonald, R. W., Griffiths, R. F., and Hall, D. J.: An improved method for the estimation of surface roughness of obstacle arrays, Atmos. Environ., 32, 1857-1864, 1998.

Medici, D.: Wind turbine wakes - control and vortex shedding, KTM Mechanics, Royal Institute of Technology, Stockholm, 2004.

Pacala, S. and Socolow, R.: Stabilization wedges: solving the climate problem for the next 50 years with current technologies, Science, 305, 968-972, 2004.

Petersen, R.: A wind tunnel evaluation of methods for estimating surface roughness length at industrial facilities, Atmos. Environ., 31, 45-57, 1997.

Schaefer, V. J.: The production of ice crystals in a cloud of supercooled water droplets, Science, 104, 457-459, 1946.

Schubert, S. D. and Suarez, M.: Dynamical predictability in a simple general circulation model: average error growth, J. Atmos. Sci., 46, 353-370, 1989.

Toth, Z. and Kalnay, E.: Ensemble forecasting at NMC: the generation of perturbations, B. Am. Meteorol. Soc., 74, 2317-2330, 1993.

Willoughby, H. E., Jorgensen, D. P., Black, R. A., and Rosenthal, S L.: Project Stormfury: a scientific chronicle, B. Am. Meteorol. Soc., 66, 505-514, 1985.

Wiser, R. and Bolinger, M.: Annual report on U.S. wind power installation, cost, and performance trends: 2006, United States Department of Energy, Office of Energy Efficiency and Renewable Energy, Washington, DOE/GO-102007-2433, 2007.

Vermeer, L. J., Sorensen, J. N., and Crespo, A.: Wind turbine wake aerodynamics, Prog. Aerosp. Sci., 39, 467-510, 2003. 